\title{
The effect of artificial intelligence technologies on audit evidence
}

\section{Saleh Mohammed Al-Sayyed ${ }^{a}$, Shaher Falah Al-Aroud ${ }^{a^{*}}$ and Lena Mustafa Zayed ${ }^{\mathrm{a}}$}

${ }^{a}$ Al Isra University - Amman - Jordan

\section{H R O N I L E}

\section{Article history:}

Received: October25, 2020

Received in revised format:

November25 2020

Accepted: December8, 2020

Available online:

December8, 2020

Keywords:

Artificial Intelligence Technologies

Audit evidence

\begin{abstract}
A B S T R A C T
Technologies of Artificial Intelligence (AI) are critical for future of the auditing profession. These technologies are actually vital tools that provide the auditing professionals with the means necessary for increasing the effectiveness and efficiency of their jobs. The aim of this study was to examine the effect of artificial intelligence technologies on audit evidence, from the point of view of certified auditors in information technology (IT) companies in Jordan. The study was used a descriptive analytical approach. The data were collected from (314 ) auditors, using a questionnaire developed for this purpose.. The findings of the study showed that expert system had effect on the audit evidence. Neural network technology did not provide any significant effect on the audit evidence. The study recommended increased interest in artificial intelligence technologies by audit offices operating in Jordan because of its scientific importance in improving the collection of audit evidence.
\end{abstract}

\section{Introduction}

The artificial intelligence (AI) science is a technical science that, by simulation of the human intelligence, expands, extends, and develops research in order to establish theory, methods, technology, and application systems. In brief, it is a computer system that has the ability to transform the human wisdom into productive work via technology. By applying AI methods, the user can greatly improve the classical information transmission process by virtue of improving the transmission speed, reducing the transmission cost, and overcoming a series of bottlenecks in problems (AI Topics, 2016). The bulky data provided by a large number of data sources and the almost unlimited computing power of cloud computing break the bottleneck that restricts development of AI and enables the implementation of a deep learning algorithm. In addition, deep learning enables the implementation of various machine learning applications and expands the scope of the AI research. Deep learning has already been involved in numerous applications. In this respect, artificial intelligence can be thought of as a 'container' of the human wisdom. Hence, development of the deep learning algorithms and methods will expand this 'container' to an extent that the humans cannot predict (Demski, 2007; Greenman, 2017).Accounting is one of the business fields in which the Information Technology (IT) techniques have been widely applied. Albeit IT was first applied in the fundamental accounting systems, financial modelling software soon later proved to be of highly-beneficial use in the analytical facets of accounting. However, the pace of IT adoption by the accounting profession was regarded as slow owing to the conservative approach of its early adopters. By the late 1990s, this profession was compelled to computerize its processes and operations as a way of enhancing their efficiency, eventually, to confront the competition and reduce the expenses (Manson, McCartney, \& Sherer, 1997, 2001). Currently, the IT tools are commonly employed in a broad range of tasks, extending from simple tasks like arithmetic computations to sophisticated ones like statistical analysis and flowcharting. Those tools encompass the logit models; checklists; toolkits; expert systems; encircling purposely-developed programs and standard software packages; audit enquiry software that can perform in-depth analysis and testing of data; internal control templates that are frequently utilized for identification of

* Corresponding author.

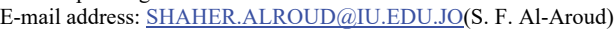


weaknesses and strengths of systems; and integrated audit monitoring modules, which are programmed routines that continually monitor real data and their processing circumstances (Omoteso,2012).

The audit profession has substantially changed over time because of technological change. Many changes in this profession have already been witnessed. They include an increase in the number and sophistication of the auditing rules, numerous changes in the standards of professional ethics, an improved quality of the audit work, growing competition among the audit firms, reduced audit fees, and provision of new services to the customers (e.g., financial and computing advices). Additionally, this profession has witnessed development of new audit types and services. These factors have together made the auditing profession more and more competitive than ever before. Accordingly, the new methods and tools provided by the IT and AI have been widely adopted by auditors. They made available more suitable and timely information to facilitate and speed up the auditor's decisionmaking process. Consequently, they improved the audit efficiency and quality (Yaniv and Bengio 2016; Zhang, Zhao, \& LeCun 2015; Silver et al., 2016; Vasarhelyi, Bonson, and Hoitash 2005).Financial audit can be defined as "the activity made by independent, skilled person for analyzing the financial and economic information that are extracted from examined accounting documents by using relevant review and verification methods. The objective of this activity is to issue report that express the auditor's opinion about reliability of that information so that this information will be known by, and of use for, a third party" (R. D. 1636/1990, Account Auditing Regulation). The audit areas wherein the expert systems can be employed are diverse and wide. They almost include every audit task, where judgment of an audit professional is required. In terms of their nature, the expert systems can be generally classified into three categories: (i) internal, (ii) external, and (iii) EDP audit expert systems. So far,auditing proved to be the accounting domain with the highest number of developed expert systems. This served as motive for the researcher to research into this area and to investigate the extent to which the audit offices in Jordan use AI techniques in evidence collection.

\section{Problem Statement}

The knowledge gaps, which are indeed sub-problems that culminated to the research problem, and which are addressed by this study, are three: First is lack of experience in the time being in the application of AI methods in the area of audit evidence in Jordan, which is an application that is still at its beginning, where even though application of automation is extensive, scope of automation is mainly restricted to financial reporting. It has not yet reached to core accounting areas like financial analysis and audit or made influence that can lead to changes in the accounting standards. When AI is incorporated into the audit work, it should replace every single step in the traditional audit work and provide proper decision-making suggestions in order to profoundly enhance the overall financial work. Thus, whether in terms of its breadth or depth, application of AI in the audit industry is still in embryo. Complexity of the AI technology and shortage of experience in its use have created big difficulties for its adoption and development. Hence, a long way is still ahead to walk for development of AI in the audit area. Second is that the quality of the professional talents that is improved by application of AI technology in the audit profession calls for professional talents to manage them, while the present senior accounting capabilities in Jordan are limited. Currently, paucity of the Jordanian accounting talents is alarming; the basic accounting personnel are in surplus whereas the top accounting talents are sparse. Within this context, integration of AI with the accounting work creates heightened demand on the accountants. So, the accounting staff do not need professional Capabilities in accounting, but they also need to master the IT and develop skill in use of the accounting software and data management in order to adapt to the developments and the associated changes in the work conditions. Lastly, the training programs of the accounting students in the universities need modification and improvement.

Currently, most of the Jordanian universities offer appropriate courses in accounting. However, affected by a number of external and internal factors, those courses have some problems associated with them like unification of the contents of the courses, lack of links between the theoretical side and the practice, and difficulty of building a Computerization of education system. These factors make it difficult to development and meet the requirements it of the profession with time. The university graduates are the main working force of the accounting profession in the future, though, in the time being, the talent training programs in those universities fail to make parallel adjustments for accounting education reform. Actually, the offered courses and training programs lack IT courses with an AI focus and pay limited attention to innovation of accounting methods and concepts. This results in lack of market competitiveness among the university graduates and in their inability to meet the future market demand on accounting professionals.

\section{Research Questions}

1. To what extent does expert system affect the audit evidence from the point of view of certified auditors of IT companies in Jordan?

2. To what extent does neural network technology affect the audit evidence from the point of view of certified auditors of IT companies in Jordan? 
The main goal of this paper is to ascertain the impact of artificial intelligence on the audit evidence from the point of view of certified auditors of IT companies in Jordan. The Sub - goals of the study included;

(i) To ascertain the effect of expert system on the audit evidence from the point of view of certified auditors of IT companies in Jordan.

(ii) To ascertain the effect of neural network technology on the audit evidence from the point of view of certified auditors of IT companies in Jordan.

The importance of the study: lies in the fact that it examines one of the new methods and new systems used in the audit process by using audit offices operating in Jordan for artificial intelligence techniques in the collection of audit evidence, which is an important element in the nature of the audit process where its importance in the accreditation of the auditor based on the composition of his professional opinion is not contrary to the international audit standards on the one hand and the legislation adopted on the other. The study takes on additional importance in two ways:

First. Theoretical importance: This importance is highlighted by the theoretical and intellectual enrichment that may contribute by tracking theoretical literature and previous studies of the key variables related to artificial intelligence in the collection of audit evidence (expert systems, neural networks) in IT companies in Jordan and in a form that is an integrated conceptual framework for these concepts and the methodology of their study. This importance also highlights the ability to make a modest contribution by tracking theoretical literature and previous studies of key variables in the form that is the conceptual and procedural framework of the study. In addition, the study will bring results to audit offices operating in Jordan in a way that helps them to take advantage of artificial intelligence techniques in collecting audit evidence.

Second: Practical importance: the practical importance of this study comes from what it can offer to decision makers in the audit offices operating in Jordan and the possibility of benefiting from its results in a way that helps them to know the importance of artificial intelligence technologies in this way in a way that does not conflict with international audit standards, and this study is important in that it will address a topic related to the extent to which audit offices use Artificial Intelligence techniques to collect audit evidence in these companies.

\section{Theoretical framework and previous studies}

\section{The Correlation between Artificial Intelligence and audit}

The AI literature is quite voluminous. It ranges from algorithmic essays (e.g., Courbariaux et al, 2016) to broad set of applications in varying research areas (e.g., Zhang, Zhao, and LeCun 2015; and Silver et al. 2016). However, research into AI in auditing is limited. Moreover, the overwhelming majority of the 'now-aged' publications are centered on the expert systems. These systems have been often advocated as systems with potential for use in tax planning and in the audit process (e.g., Bedard and Graham 1994; Graham, Damens, and Van Ness 1991). Gillett (1993) developed audit expert system (AES) to help auditors in tailoring the audit programs and described the initial steps of the long execution process (Vasarhelyi 1993). Furthermore, during the period 1989-2005, six volumes of book series were published that covered variety of the expert system applications and discussed the added values which these systems lent to accounting and auditing (Vasarhelyi and Kogan 1989; Vasarhelyi and O'Leary 2005; Vasarhelyi, Bonson, and Hoitash (2005). study conducted by Andrea Rosarioet al., (2017). Research Ideas for Artificial Intelligence in Auditing: The Formalization of Audit and Workforce Supplementation. This paper suggested different fields of AI-related projects to examine where this emerging technology is most promising. Moreover, this paper suggested a concatenation of methodological research questions aiming to study the AI-driven transformation of today's world of audit. BAI (2017).This paper studied of the application of artificial intelligence in the field of audit services in major international accounting firms, This study investigated in the impact of artificial intelligence on the audit and the relevant auditing practitioners and responsible. To take an in-depth analysis of the coping strategies. study Julia Kokina and Davenport (2017). They discussed of the emergence of artificial intelligence in accounting and auditing and the current capabilities of Knowledge technologies and the implications these technologies will have on human auditors and the audit process itself. and also They provided industry examples of artificial intelligence implementations. The same context Omoteso (2012) via The application of artificial intelligence in auditing: Looking back to the future. discussed the significance of auditors' use of artificial intelligent systems in arriving at audit judgements. Specifically, it reviewed research efforts on the use of expert systems and neural networks in auditing and the implications thereof. Gusai (2019). This study aimed To study the importance of artificial learning in accounting and auditing areas and measure the decree of forthcomings regarding artificial intelligence in accounting. Conclusion This study AI paves way for a better and conducive environment in the field of accounting and auditing. Development in the field of AI can definitely be a great help to human efforts. Greenman (2017). this study investigated the Impact of Artificial Intelligence on the Accounting Profession. The Prospective tasks of bookkeeping or process-driven assignments are more likely to be replaced with an automated technology than the higher value specialties that involve professional judgment. Many believe that the younger generation of accountants need to understand and be prepared to work alongside artificial intelligence. Zehong Li, Li Zheng (2018). This study investigated on use artificial intelligence to avoid 
accounting fraud and to generate positive impact on accounting information quality, this article analyzed the paper intelligence effect the accounting. The results of the study arrived that artificial intelligence, accounting should improve its own seven aspects of abilities and become a comprehensive qualified personnel. Luo et al. (2018). This paper examined the artificial intelligence in the accounting industry as the research object, analyzesed the impact of artificial intelligence on the development of accounting and puts forward And suggestions for its problems. Chukwudi al. (2018) they investigated the effect of artificial intelligence on the performance of accounting operations in accounting firms in Nigeria. the study confirmed that Expert system ha effect on the performance of accounting function of accounting firms in Nigeria. It was concluded that, artificial intelligence influences the performance of accounting functions.

\section{Research Hypothesis}

As contained in the statement of objectives, it is logical to identify relationship between (artificial intelligence and audit evidence) that now form the bases of the hypotheses of the study. The resultant hypotheses formulated in order to carry out this research are as follow;

H01: Expert system has no significant effect on the audit evidence from the point of view of certified auditors of IT companies in Jordan.

H02: Neural networks has no significant effect on the audit evidence from the point of view of certified auditors of IT companies in Jordan.

\section{Research Methodology}

Research design is very crucial to actualize the research objectives (Bhatti et al., 2012). This study applied a quantitative research design. Quantitative research design will enable the researcher to test the relationship between the research variables. It will also enable the researcher to unvaryingly determine if one concept or idea is better than the others. It can also respond to questions on the relationships that exist among measured variables with the aim of elucidating, envisaging, as well as controlling phenomena (Sekaran \& Bougie, 2016). Thus, quantitative research design is an appropriate method for this study since it permits testing the relationship between variables with the use of statistical approaches. This is in line with the main objective of this study that focus. Thus, quantitative research design is an appropriate method for this study since it permits testing the relationship between variables with the use of statistical approaches. (Sekaran \& Bougie, 2016). This is in line with the main objective of this study that to examine the extent to which audit offices in Jordan use artificial intelligence technologies to collect audit evidence, from the point of view of certified auditors in IT companies in Jordan Therefore, the specific question quantitative research also permits to carry out analysis using large sample to generalize the results among a set of population. Population and sample of the study.

\subsection{Population and Sampling}

Sekaran (2006) defined population as the entire group of people, events, or things of interest that the researcher wishes to investigate. The population size of this study consists of (582) licensed auditors and practitioners and exercises the audit function of the 220 IT companies registered in the Association of Information Technology Companies in Jordan. As stated by Sekaran and Bougie (2016), "the level of aggregation of the data collected during the subsequent data analysis stage" is known as a unit of analysis. Therefore, the unit of analysis is individual based, means that data was collected from licensed auditors and practitioners is the unit of analysis of the study. There are two types of sampling methods which arenon-probability and probability samplings. The researchers in this study opted probability sampling method which is inferred as simple random sampling technique. By that, each aspect pertaining to the selected population may be represented in the sample.As recommended by Krejcie and Morgan (1970), the appropriate sample size for a population size of 582 is 274 . In order to lessen sample size error and putting into consideration the occurrence of non-response by some respondents, the sample size was increased by as suggested by Barlett, et al. (2001). Therefore, the sample size of this study had become by $(274+40=314)$. Hence, 314 questionnaires were distributed to the sample, eleven of them were excluded because they were not filled completely or correctly so (303) questionnaires were valid.

\subsection{Instrument for Data Collection}

Data used in this study gotten from primary sources obtained from the study instruments. The study used primary data that were collected from The study sample by the questionnaire, defined questionnaire as measuring instruments that ask individuals to answer a set of questions or responding to a set of a statement. The questionnaire used comprised of Likert Scale this was intended to get the depth of information and data that was analyzed to realize the objectives of the study.

\subsection{Data Analysis Techniques}

The main goal of this study is to test the hypotheses in line with the study's Research Objectives . As this study is quantitative , it intends to empirically justify the proposed theoretical frame by analysing of the relationships between variables. two major 
analyses were involved. The first is descriptive analysis and test the research hypotheses by were used within the program (SPSS Statistical Package for Social Science.

\subsection{Validity and Reliability of the Instrument}

The researchers subjected the questionnaire to ensure validity and content validity by giving it to six experts in field artificial intelligence and and accounting, who studied the instrument thoroughly to ensure they are in line with the objectives of the study. Procedurally, the researchers pre tested thirty (30) questionnaires before the actual survey for the study. The responses obtained from survey were subjected to the Cronbach Alpha's internal consistency test via (SPSS). Based on the inter-item correlation of Twelve (16) items on the questionnaire the result of the reliability test is 0.88 . Since the item on the questionnaire were uniformly scaled and in accordance to the Sekaran, (2006). Cronbach's alpha must be 0.700 or Larger. Cronbach's alpha Coefficient of (0.88), shows that the items the questionnaire are internally consistent, hence they are reliable.

\section{Data Analysis and Presentation}

First. results of descriptive statistics: Means and standard deviations to the extent to which audit offices in Jordan use expert systems technology to collect audit evidence., and the following tables show the results from the point of view of the study sample members, as follows:

Table 1

Means and standard deviations for expert systems

\begin{tabular}{|c|c|c|c|c|}
\hline Items rank & Items & Mean & $\begin{array}{l}\text { Standard } \\
\text { deviation }\end{array}$ & $\begin{array}{c}\text { Degree of } \\
\text { importance }\end{array}$ \\
\hline 4 & $\begin{array}{l}\text { Application software based on knowledge bases is used in a particular area } \\
\text { of expertise. }\end{array}$ & 3.776 & .7299 & High \\
\hline 8 & $\begin{array}{l}\text { Expert systems are used to collect audit evidence by reformulating them in } \\
\text { the form of computer-hosted software. }\end{array}$ & 3.564 & .6804 & High \\
\hline 2 & $\begin{array}{l}\text { Expert systems are used to extract knowledge to resolve problems with the } \\
\text { collection of audit evidence. }\end{array}$ & 3.905 & .6835 & High \\
\hline 7 & $\begin{array}{l}\text { Advanced software languages are used to improve the collection of audit } \\
\text { evidence. }\end{array}$ & 3.670 & .8221 & High \\
\hline 1 & $\begin{array}{l}\text { Expert systems are used to be able to advise and make the right decisions } \\
\text { regarding audit evidence. }\end{array}$ & 3.917 & .6212 & High \\
\hline 6 & $\begin{array}{l}\text { Knowledge and control of the search for audit evidence are represented } \\
\text { within databases. }\end{array}$ & 3.694 & .6730 & High \\
\hline 3 & $\begin{array}{l}\text { The expert system is used as a hierarchical frame that reflects the accounting } \\
\text { knowledge set for audit evidence. }\end{array}$ & 3.858 & .6006 & High \\
\hline 5 & $\begin{array}{c}\text { The expert system is used to collect audit evidence to be encrypted in a } \\
\text { program and stored in the system's knowledge base. }\end{array}$ & 3.752 & .7385 & High \\
\hline & Total & 3.767 & \multicolumn{2}{|c|}{ High } \\
\hline
\end{tabular}

Table lindicates that the total mean of the extent to which audit offices in Jordan use the technology of expert systems in the collection of audit evidence, from the point of view of certified auditors in IT companies in Jordan, have reached a high level of (3.767). The standard deviations of the terms covered by this variable indicate the extent to which the values of this variable are dispersed from the means of all items, noting that they are low and indicate that the responses of the sample study are very similar and consisting.

Table 2

Means and standard deviations for collect audit evidence

\begin{tabular}{|c|c|c|c|c|}
\hline $\begin{array}{c}\text { Items } \\
\text { rank }\end{array}$ & Items & Mean & $\begin{array}{r}\text { Standard } \\
\text { deviation }\end{array}$ & $\begin{array}{l}\text { Degree of } \\
\text { importance }\end{array}$ \\
\hline 3 & $\begin{array}{l}\text { Neural network technology is used to complete the collection and practical implementation of integrated } \\
\text { electronic audit evidence. }\end{array}$ & 3.835 & .6874 & High \\
\hline 5 & $\begin{array}{l}\text { Neural networks are used to store information about the collection of evidence for the collection of links and } \\
\text { communications. }\end{array}$ & 3.729 & 6967 & High \\
\hline 4 & Electronic processing units are available for the collection of neurons that make information available to users. & 3.788 & .6967 & High \\
\hline 8 & $\begin{array}{l}\text { Neural networks are used in mathematical models of audit guides formulated in diagrams that mimic the qualities } \\
\text { found in computer systems. }\end{array}$ & 3.588 & .8351 & High \\
\hline 6 & $\begin{array}{l}\text { Neural networks are used to process information on audit evidence and provide solutions to complex problems in } \\
\text { parallel. }\end{array}$ & 3.564 & .6804 & High \\
\hline 2 & $\begin{array}{l}\text { Neural networks contribute to providing solutions and recommendations to the user in a clear and accurate } \\
\text { picture about the evidence of auditing }\end{array}$ & 3.904 & .6835 & High \\
\hline 7 & $\begin{array}{l}\text { Neural networks allow the user to enter instructions and information related to audit evidence to obtain } \\
\text { accounting information }\end{array}$ & 3.670 & .8221 & High \\
\hline 1 & $\begin{array}{l}\text { Neural networks can explain the steps of collecting audit evidence to reach the solution and the reasons behind } \\
\text { this solution }\end{array}$ & 3.917 & .6212 & High \\
\hline & Total & 3.749 & \multicolumn{2}{|c|}{ High } \\
\hline
\end{tabular}


Table 2 indicates that the total means of the extent to which audit offices in Jordan use neural network technology to collect audit evidence, from the point of view of certified auditors in IT companies in Jordan, have reached a high level of (3.749). The standard deviations of the terms covered by this variable indicate the extent to which the values of this variable are dispersed from mean of all items, noting that they are low and indicate that the responses of the sample study are very similar and consisting.

\subsection{Hypotheses Testing}

The data collected from the Sample was analyzed. Inferential statistic of regression analysis was used in testing the study hypotheses at 5\% level of significance. The decision will be, Reject H0 if the p-value is less than 0.05 .

\section{Hypothesis One}

Expert system has no significant effect on the audit evidence from the point of view of certified auditors of IT companies in Jordan.

Table 3

Results of Regression analysis for expert system and audit evidence:

\begin{tabular}{ccccc}
\hline $\mathbf{R}$ & R square & F-statistic & Sig & t-test \\
\hline .906 & .847 & 709.457 & .000 & 24.767 \\
\hline
\end{tabular}

Table (3) shows a multiple linear regression analyse. the findings of the study shows that there was a strong positive significant relationship between expert system and audit evidence from the point of view of certified auditors of IT companies in Jordan. $(\mathrm{R}=.906, \mathrm{R}$ square $=.847, \mathrm{~F}$-statistic $=709.457, \mathrm{t}=24.767 ; \mathrm{p} \leq 0.05)$ indicating a Height in expert system yielded 24.767 changes in audit evidence at 0.05 level of significance. Therefore, the alternate hypothesis accepted and the null hypothesis is rejected. "expert system has significant influence on audit evidence in IT companies in Jordan.

\section{Hypothesis Two}

Neural network has no significant effect on the audit evidence from the point of view of certified auditors of IT companies in Jordan.

\section{Table 4}

Results of Regression analysis for neural network technology and audit evidence:

\begin{tabular}{ccccc}
\hline $\mathbf{R}$ & R square & F-statistic & Sig & t-test \\
\hline 0.081 & 0.006 & 0.525 & 0.470 & 0.724 \\
\hline
\end{tabular}

Table (4) shows the linear regression result of neural network technology and audit evidence from the point of view of certified auditors of IT companies in Jordan. The result which sort to reveal the not effect of neural network technology on audit evidence, revealed that there is not strong positive relationship between neural network technology and audit evidence (Rcoefficient $=0.081$ ). The $\mathrm{R}$ square, the coefficient of determination, shows that 0.006 of the variation in audit evidence can be explained by neural network technology. The extent to which neural network technology affect audit evidence with the 0.081 value indicates not positive significance between neural network technology and audit evidence $(\mathrm{F}-\mathrm{statistics}=0.525 ; \mathrm{t}=$ 0.724 ) and $\mathrm{p}=0.470$. Therefore, the null hypothesis is accepted and the alternate hypothesis rejected, hence "neural network technology has not effect on the audit evidence".

\section{8. conclusions}

Even though Artificial Intelligence provides promising outlook for the future, most researchers and organizations have to adopt the necessary skills and knowledge. From the researchers' experience, there is a need to assess the impact of AI on audit evidence. Therefore, the purpose of this study was to explore the impact of AI Intelligence on audit evidence in order to the acquisition to skills and knowledge.

The present study takes a contemporary issue on the integration of Artificial Intelligence in audit evidence which tries to look at the universal questions raised by investigators or researchers. The two fundamental questions addressed in this study: To what extent does expert system affect the audit evidence from the point of view of certified auditors of IT companies in Jordan, and To what extent does neural network technology affect the audit evidence from the point of view of certified auditors of IT companies in Jordan. This is the research problem addressed by this study. The information from this study will help the researchers to learn more about the impact of AI in audit evidence from the point of view of certified auditors in IT companies in Jordan. In this study, the primary source was based on some questionnaire conducted noncertified auditors in IT companies in Jordan. 


\section{Recommendations}

Based on the findings of the study, it is recommended the following:

1. Increased interest in Artificial Intelligence technologies by audit offices operating in Jordan since it is practically important in improving the collection of audit evidence.

2. Emphasize the need to use sophisticated software languages and encrypt them in a program and save them in the system's knowledge base to improve the collection of audit evidence.

3. Emphasize the importance of using neural networks in mathematical models of audit guides formulated in diagrams that mimic the qualities found in computer systems.

4. Audit offices operating in Jordan must provide electronic processing units for the collection of audit evidence in the form of neurons that make information available to users.

5. Focus on training auditors to keep pace with technological advances in AI applications in collecting audit guides, representing knowledge, and controlling the search for such evidence within databases.

6. Importance of relying on the use of smart software to develop the process of collecting and reformulating audit evidence in the form of computer-embraced software for its role in improving the quality of the audit process.

7. Make better use of neural networks especially with regard to providing solutions and the reasons behind this solution and recommendations to the user in a clear and accurate form about the audit guides.

8. Pay more attention to giving auditors many opportunities to develop and practice the application of artificial intelligence methods because of their importance in improving the collection of audit evidence.

\section{References}

AI Topics. (2016). Brief History of Artificial Intelligence. http://aitopics.org/topic/brief-histories-timelines.

BAI, G. H. (2017). Research on the Application and Influence of Auditing Artificial Intelligence. DEStech Transactions on Social Science, Education and Human Science, (eiem).

Bedard, J. C., \& Graham Jr, L. E. (1994). Auditors' knowledge organization: Observations from audit practice and their implications. Auditing, 13(1), 73.

Bhatti, M. A., Hoe, C. H., \& Sundram, V. P. K. (2012). A guide for beginners data analysis using SPSS and AMOS. Pearson Malaysia.

Chukwudi, O. L., Echefu, S. C., Boniface, U. U., \& Victoria, C. N. (2018). Effect of Artificial Intelligence on the Performance of Accounting Operations among Accounting Firms in South East Nigeria. Asian Journal of Economics, Business and Accounting, 7(2), 1-11.

Courbariaux, M., Hubara, I., Soudry, D., El-Yaniv, R., \& Bengio, Y. (2016). Binarized neural networks: Training deep neural networks with weights and activations constrained to +1 or-1. arXiv preprint arXiv:1602.02830.

Graham, L. E., Damens, J., \& Vanness, G. (1991). Developing risk advisorism-An expert system for risk identification. Auditing-a Journal of Practice \& Theory, 10(1), 69-96.

Greenman, C. (2017). Exploring the impact of artificial intelligence on the accounting profession. Journal of Research in Business, Economics and Management, 8(3), 1451.

Gusai, O. P. (2019). Robot human interaction: role of artificial intelligence in accounting and auditing.Indian Journal of Accounting (IJA), 51(1), 59-62.

Demski, J. S. (2007). Is accounting an academic discipline?. Accounting Horizons, $21(2), 153$.

He, K., Zhang, X., Ren, S., \& Sun, J. (2015). Spatial pyramid pooling in deep convolutional networks for visual recognition. IEEE Transactions on Pattern Analysis and Machine Intelligence, 37(9), 1904-1916.

Griffin, O. (October, 2016). How artificial intelligence will impact accounting. Economia.

Issa, H., Sun, T., \& Vasarhelyi, M. A. (2016). Research ideas for artificial intelligence in auditing: The formalization of audit and workforce supplementation. Journal of Emerging Technologies in Accounting, 13(2), 1-20.

Krejcie, R. V., \& Morgan, D. W. (1970). Determining sample size for research activities. Educational and Psychological Measurement, 30(3), 607-610.

Luo, J., Meng, Q., \& Cai, Y. (2018). Analysis of the impact of artificial intelligence application on the development of accounting industry. Open Journal of Business and Management, 6(4), 850-856.

Kokina, J., \& Davenport, T. H. (2017). The emergence of artificial intelligence: How automation is changing auditing. Journal of Emerging Technologies in Accounting, 14(1), 115-122.

Manson, S., McCartney, S., \& Sherer, M. (1997). Audit automation: The use of information technology in the planning, controlling and recording of audit work. Edinburgh: ICAS. 
Manson, S., McCartney, S., \& Sherer, M. (2001). Audit automation as control within audit firms. Accounting, Auditing and Accountability Journal, 14(1), 109-130.

Omoteso, K. (2012). The application of artificial intelligence in auditing: Looking back to the future. Expert Systems with Applications, 39(9), 8490-8495.

Sekaran, U., \& Bougie, R. (2016). Research methods for business: A skill building approach. John Wiley \& Sons.

Sekaran, U. (2006). Research Methods for Business: A Skill Building Approach. John Wiley \& Sons.

Silver, D., Huang, A., Maddison, C. J., Guez, A., Sifre, L., Van Den Driessche, G., ... \& Dieleman, S. (2016). Mastering the game of Go with deep neural networks and tree search. Nature, 529(7587), 484-489.

Sun, T., \& Vasarhelyi, M.(2016). Sentiment Features of Conference Calls and Internal Control Quality: An Application of Deep Learning Technology. Working paper, Rutgers, The State University of New Jersey.

Vasarhelyi, M., \& Kogan, A. (1989). Artificial Intelligence and Expert Systems in Accounting and Auditing. Vol. 1. Princeton, NJ: Markus Wiener Publishers.

Vasarhelyi, M., \& O’Leary, D. (2005). Artificial Intelligence in Accounting and Auditing: Adding Value to Business. Vol. 5. Princeton, NJ: Markus Wiener Publishers.

Vasarhelyi, M., Bonson, E., \& Hoitash, R. (2005). Artificial Intelligence in Accounting and Auditing: International Perspectives. Vol. 6. Princeton, NJ: Markus Wiener Publishers.

Zehong Li, Li Zheng (2018). The Impact of Artificial Intelligence on Accounting. Advances in Social Science, Education and Humanities Research (ASSEHR), volume 181, th International Conference on Social Science and Higher Education (ICSSHE).

Zhang, X., Zhao, J., \& LeCun, Y. (2015). Character-level convolutional networks for text classification. In Advances in Neural Information Processing Systems, 28, 649-657.

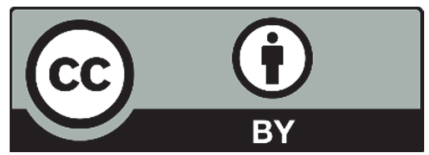

(C) 2021 by the authors; licensee Growing Science, Canada. This is an open access article distributed under the terms and conditions of the Creative Commons Attribution (CC-BY) license (http://creativecommons.org/licenses/by/4.0/). 